\title{
Der Platz der Plätze
}

Erhard Taverna

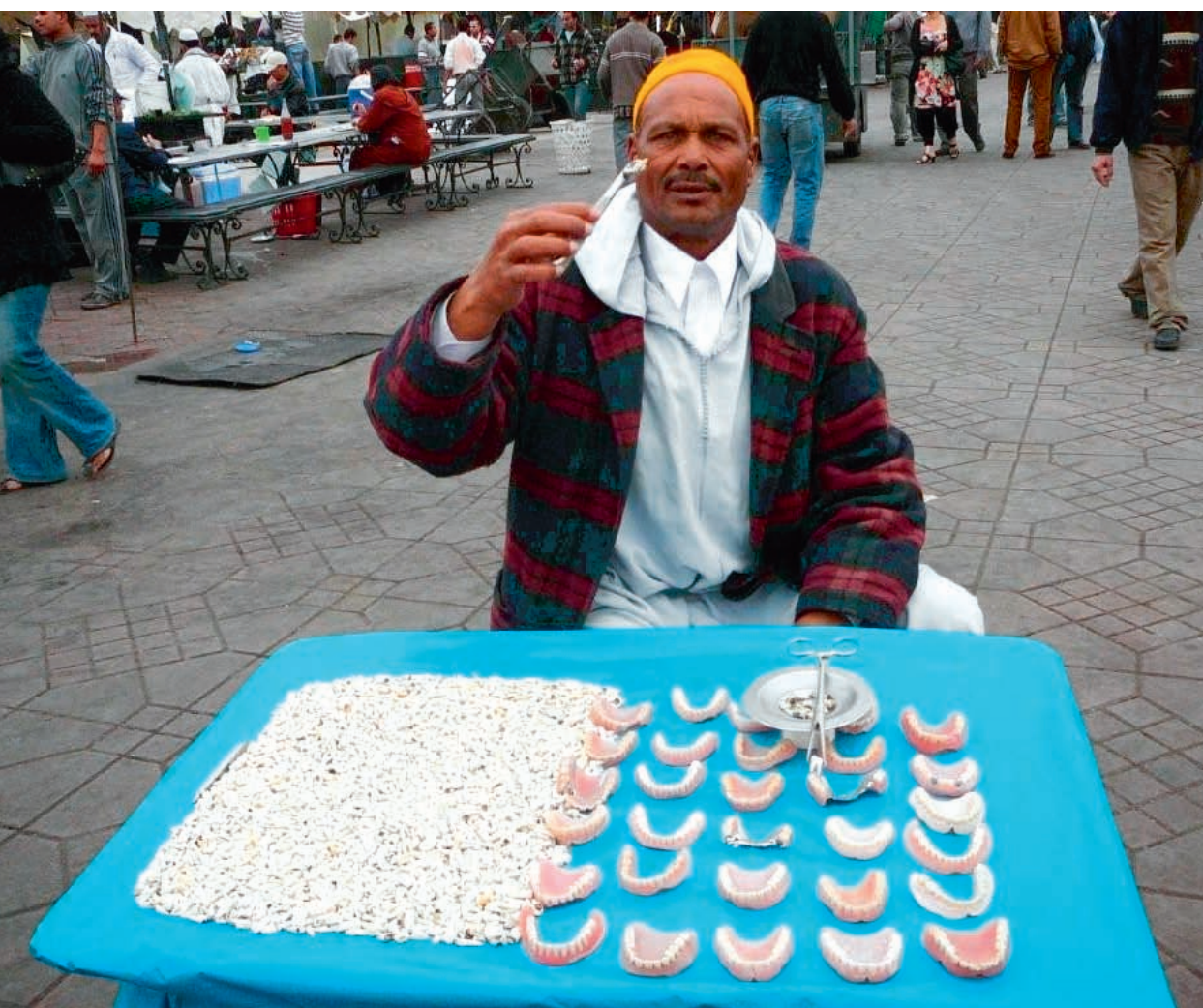

Der Wind bläst den Rauch der vielen Garküchen durch die vollbesetzten Bänke. Weissgekleidete Kellner und Köche kämpfen um die unschlüssigen Touristen, die, zwischen Hunger und Ekel hin- und hergerissen, dem heftigen Werben erliegen. Das europäische Auge sucht nach dem halbwegs Bekannten, vermeidet Hammelhirne und Eingeweide und überlässt die Tieraugen und Schnecken den Einheimischen. Vom frühen Abend bis in den späten Morgen verwandelt sich die Platzmitte in ein brodelndes Fresslager mit babylonischem Sprachgewirr unter Zeltstangen und Segeltuch, Glühbirnen und Scheinwerfern, umgeben von einer Wagenburg aus Orangenverkäufern und weiteren Imbissbuden. Ausserhalb locken die Gaukler und Wahrsager mit Schellengeschüttel und Tamburin. Eine müde Kobra wird wie ein Stück Holz über den Asphalt geschoben, ein Affe soll die Kinder zu Fotos animieren, Wasserverkäufer in spitzen Fransenhüten bieten sich als bezahlbare Kulisse an. Wer möchte, kann sich die Hände mit Henna bemalen oder nebenan sein Horoskop berechnen lassen. Auch hier hat die Medizin am meisten Gaffer. Ein junger Mann mit braunem Turban lockt in Scharen Patienten und Neugierige. Seine hervorragende Pantomime ersetzt mühelos die fehlenden Sprachkenntnisse. Er rollt die Augen und legt seine Hand auf die schmerzenden Körperstellen. Unablässig redend zeigt er auf den vollbelegten Tisch, rührt in Gläsern und Kannen, mischt Kräuter, lässt die vordersten Zuschauer daran schnuppern und nimmt dann selber einen Schluck von seinem Gebräu. Diagnose, Therapie und Heilung sind mimisch perfekt inszeniert, er leidet, doziert und mischt, er lässt die Patienten auf einem Stuhl Platz nehmen und formt die Neugierigen $\mathrm{zu}$ seiner therapeutischen Hilfstruppe, die hoffend und bangend den Meister begleitet, dessen Gebärden die zu erwartende Erlösung vorwegnehmen. Dann kommt der grosse Moment, wo die Klienten den Kopf weit nach hinten beugen und sich aus der Thermosflasche eine zähflüssige, honiggelbe Flüssigkeit in die aufgesperrten Münder ergiesst. Ein erlösendes Raunen geht durch die Menge, eine Note wechselt die Hand, und der oder die nächste nimmt Platz.

Nachts sind heiklere Problemlösungen angesagt. Die Zuhörer sind ausschliesslich junge Männer, die regungslos die weiblichen und männlichen Schnittbilder anatomischer Schautafeln betrachten. Auch hier wird eindringlich erklärt und geblättert und auf farbige Pulver, getrocknete Pflanzen, Reptilienhäute und dekorative Strausseneier verwiesen, die, fachkundig vermischt, Potenz und ewige Liebe garantieren. Wo Herboristen und Heilkundige ihr Können anpreisen, ist auch der Zahnarzt nicht weit. Blekkende Gebissreihen versprechen Erlösung von Karies und geschwollenen Backen. Stolz präsentiert ihr Besitzer die gezogenen Zähne auf seinem Verkaufstisch. Das Werkzeug hält er diskret versteckt, denn hier werden nur Termine ausgehandelt.

Schlank bis mager sind hier die meisten, ausser den vielen rosigen, oft übergewichtigen Europäern, die beim geringsten Problem in ihre Kliniken nach Hause düsen. Die exotische Volksmedizin hat nichts mit unserer alternativen Wohlfühlkultur gemeinsam. Wer hier kein Geld hat, erhält gar nichts, keine Pille, keinen Arzt, 
keine Leistung. Wo das Pülverchen versagt, hilft nur noch das Gebet, denn das scheinbar Exotische hat einen hohen Preis. Der Djama al-Fna, früher der Platz der Gehenkten, ist heute attraktiver Mittelpunkt von Marrakesch, berühmt und berüchtigt für seine Gegensätze. Marokkoreisen sind heute im Trend, in das Land wird investiert, die französische Sprache ist allgegenwärtig, wie Armut und Reichtum, wie Frömmigkeit und Willkür. Wer in den kulturellen Gegensätzen mehr als Fotosujets entdecken möchte, ist gut beraten, den Islamwissenschaftler, Poeten und Philosophen Stefan Weidner, geboren 1967, kennenzulernen. Bekannt wurde er mit seinem Buch «Mohammedanische Versuchungen» [1], einer spannend geschriebenen «Erkundung über das autoritäre Regelwerk des Koran». In seinem neuen Buch «Fes» [2] beschreibt er den bekannten Ort der Kontraste: «Er ist es, der Platz. Der
Platz der Plätze. Djama al-Fna. Auslöschungsplatz. Der Platz der Gehenkten. Hinrichtungsstätte oder Ort der Ekstase und Himmelfahrt, Nabel der Welt oder Tag des Jüngsten Gerichts, Zirkus und Börse, Sklavenmarkt oder Konzentrationslager. Bühne, wo alles sich abspielt. Das Forum, der Marktplatz der Existenz. In einer Welt ohne Orte ein Ort, ein archimedischer Punkt. Sinnlos, dies zu erklären und zu beschreiben. Man weiss und empfindet es, wenn man dort ist. Hier ist man zu Hause. Hierhin mündet man immer auch selbst.»

1 Stefan Weidner. Mohammedanische Versuchungen. Zürich: Ammann; 2004. 238 Seiten.

2 Stefan Weidner. Fes. Zürich: Ammann; 204 Seiten. 2006. 